\title{
Perancangan Sistem Informasi Pencatatan Form Order Berbasis Web pada PT. United Trans Perkasa
}

\author{
Yulianus Palopak $^{* 1}$, Romario S.L. Tobing² \\ ${ }^{1}$ Dept. Information Engineering, National Taiwan University of Science and Technology, Taiwan \\ ${ }^{2}$ PT United Trans Perkasa, Indonesia \\ e-mail: ${ }^{* 1}$ yulianus.palopak@gmail.com, romario.t@unitedtransperkasa.com
}

\begin{abstract}
Abstrak
Perkembangan teknologi informasi saat ini sangat mempengaruhi berbagai jenis pekerjaan di dunia ini. Tidak terkecuali bagi sebuah perusahaan, jika ingin terjun dalam persaingan maka sedapat mungkin perusahaan tersebut harus menggunakan teknologi dalam mendukung proses bisnis yang dilakukan. Berkenaan dengan itu, salah satu alasan dibuatnya penelitian ini adalah karena PT. United Trans Perkasa belum memiliki sistem yang terkomputerisasi dalam proses bisnis perusahaan tersebut terutama dalam hal pengelolaan data order. Tujuan penelitian ini adalah: (1) mempermudah perusahaan mencari data order yang sudah dicatat, (2) mempermudah pekerja dalam mengetahui datangnya order dari setiap customer, dan (3) mempermudah pekerja dalam mengirim data-data yang perlu dilaporkan ke pimpinan perusahaan. Perancangan sistem ini menggunakan Metode Waterfall, yang melakukan pendekatan proses perancangan secara sistematis, yang dimulai pada tingkat analisa sistem, desain, kode, dan pengujian. Adapun kesimpulan dari penelitian ini adalah: (1) Sistem informasi pencatatan form order pada PT. United Trans Perkasa adalah sistem yang dibuat untuk mempermudah pekerjaan dan juga meningkatkan pelayanan dalam melayani para customer, (2) Sistem informasi pencatatan form order pada PT. United Trans Perkasa dapat menyajikan data yang penting dalam perusahaan secara terkomputerisasi dan juga berbasis online, sehingga data tersebut bisa diakses oleh pekerja kantor di mana dan kapan saja. (3) Sistem informasi pencatatan form order pada PT. United Trans Perkasa juga dapat memudahkan pihak perusahaan dalam mengecek customer yang ingin menggunakan jasa perusahaan, karena sistem ini terhubung dengan website perusahaan.
\end{abstract}

Kata kunci: form order, pencatatan data perusahaan, program, Waterfall.

\section{Designing Order Form Recording Web-based Information System at PT. United Trans Perkasa}

\begin{abstract}
The evolution of information technology greatly affects various types of jobs in this world. Business competition encourages companies to use technology for support business processes. One of the fundamental reasons for this research's PT. United Trans Perkasa doesn't yet have a computerized system in the company's business processes, especially in terms of managing data orders. The purpose of this study are: (1) Makes it easier for companies to find the order data that has been recorded, (2) Makes it easier for workers to know the arrival of orders from each customer, and (3) Makes it easier for workers to send data that needs to be reported to the leadership of the company. The design of this system uses the Waterfall Method, which approaches the design process systematically, which starts at the level of system analysis, design, code, and testing. The conclusions of this study are: (1) Information system for recording the order form at PT. United Trans Perkasa is a system created to simplify work and also improve services in serving customers, (2) Information system for recording order forms at PT. United Trans Perkasa can present important data in a computerized company and also based online, so that the data can be accessed by office workers anywhere and anytime. (3) Information system for recording the order form at
\end{abstract}


PT. United Trans Perkasa can also facilitate the company in checking customers who want to use company services, because this system is connected to the company's website.

Keywords: Order Form, Company Data Recording, Program, Waterfall Method.

\section{Pendahuluan}

Dengan berkembangnya teknologi informasi, maka sistem yang ada di suatu perusahaan yang tadinya menggunakan proses manual yaitu dengan menulis tangan ke buku atau kertas, sekarang berubah dengan memasukan data itu ke komputer sehingga menjadi data digital. Oleh karena itu sudah seharusnya setiap perusahaan menggunakan teknologi komputerisasi pada perusahaannya.

Salah satu perusahaan yang membutuhkan sistem terkomputerisasi adalah perusahaan yang bergerak dalam bidang jasa ekspedisi. Sekarang ini perusahaan ekspedisi sudah seharusnya menggunakan sistem terkomputerisasi demi melancarkan proses kerja pada perusahaan. Karena perusahaan jasa ekspedisi membutuhkan penyajian data yang cepat dan mudah didapatkan.

Perusahaan ekspedisi yang akan dibahas disini adalah PT. United Trans Perkasa. Saat ini sistem yang di gunakan oleh perusahaan ini masih menggunakan sistem manual, yaitu dengan menuliskan pesananpesanan tersebut ke dalam buku form order. Prosedurnya adalah, pelanggan menghubungi PT. United Trans Perkasa untuk mengirimkan barang mereka ke daerah tertentu, lalu pihak perusahaan segera memproses berbagai macam hal yang dibutuhkan untuk mengirim barang tersebut, seperti surat izin dan lain-lain. Setelah itu maka barang di kirim, dan setelah sudah tiba di tujuan, maka PT. United Trans Perkasa membuat invoice dan dikirimkan kepada perusahaan pengguna jasa. Setelah perusahaan pengguna jasa melakukan pembayaran, maka data pesanan tadi dimasukkan ke dalam buku form order.

Kesulitan yang dihadapi oleh perusahaan ini adalah proses penataan data yang belum rapi, karena masih menggunakan cara manual yaitu mencatat data order ke dalam kertas. Data kas kecil yang seharusnya di tata dengan rapih, terkadang hilang karena proses pencatatannya masih menggunakan kertas. Untuk memudahkan para pekerja di perusahaan ekspedisi tersebut dalam mencatatkan data dan mengolah data, maka diusulkan suatu sistem pencatatan form order berbasis web. Diharapkan dengan aplikasi ini, informasi berupa data dalam jumlah yang banyak dapat diatur dan diolah sedemikian rupa sehingga prosesnya tidak memakan banyak waktu.

\section{Sistem Informasi}

Sistem informasi adalah suatu sistem di dalam suatu organisasi yang mempertemukan kebutuhan pengelolaan transaksi harian, mendukung operasi, bersifat manajerial, dan kegiatan strategi dari suatu organisasi dan menyediakan pihak luar tertentu dengan laporan-laporan yang dibutuhkan [1].

\section{Website}

Website adalah suatu sistem yang berkaitan dengan dokumen digunakan sebagai media untuk menampilkan teks, gambar, multimedia dan lainnya pada jaringan internet [2].

\section{Basis data}

Basis data dapat dikatakan sebagai kumpulan file yang disimpan di dalam komputer secara sistematik dan saling berhubungan. Hubungan tersebut biasa ditunjukkan dengan kunci dari tiap file yang ada. Suatu basis data menunjukkan suatu kumpulan data yang dipakai dalam suatu lingkup organisasi. Basis data menjadi salah satu bagian penting dari perusahaan untuk menyimpan informasi-informasi yang diinginkan perusahaan tersebut [3]. 


\section{Metode Penelitian}

\section{Metodologi Waterfall}

Model waterfall ini sering disebut juga model sekuensial linier (sequential linier). Model air terjun menyediakan pendekatan alur hidup perangkat lunak secara sekuensial atau urut dimulai dari analisis, desain, pengkodean, pengujian dan tahap support [4].

\section{Analisa Kebutuhan Fungsi Sistem}

Dari penelitian ini diperlukan beberapa fungsi yang dapat mendukung kerja sistem tersebut. Adapun fungsi-fungsi yang dibutuhkan user adalah sebagai berikut:

1. Menyimpan data order perusahaan

2. Menyimpan data kas kecil (petty cash) perusahaan

3. Menu to do

4. Mengirim laporan dari halaman admin ke halaman master

5. Menyimpan data contact us dari website perusahaan

6. Menyimpan data pemesanan online

7. Menyimpan data kontak customer.

\section{Hasil}

\section{Diagram Konteks Sistem Informasi Form Order}

Diagram konteks adalah diagram yang digunakan untuk menjelaskan konteks dan batasan dari sistem yang sedang dimodelkan, apakah itu sesuatu yang berada di dalam atau di luar sistem tersebut, dan juga menjelaskan hubungan antara sistem tersebut dengan entitas yang berada di luar sistem [5].

Berikut diagram konteks dari Sistem Informasi Form Order ini.

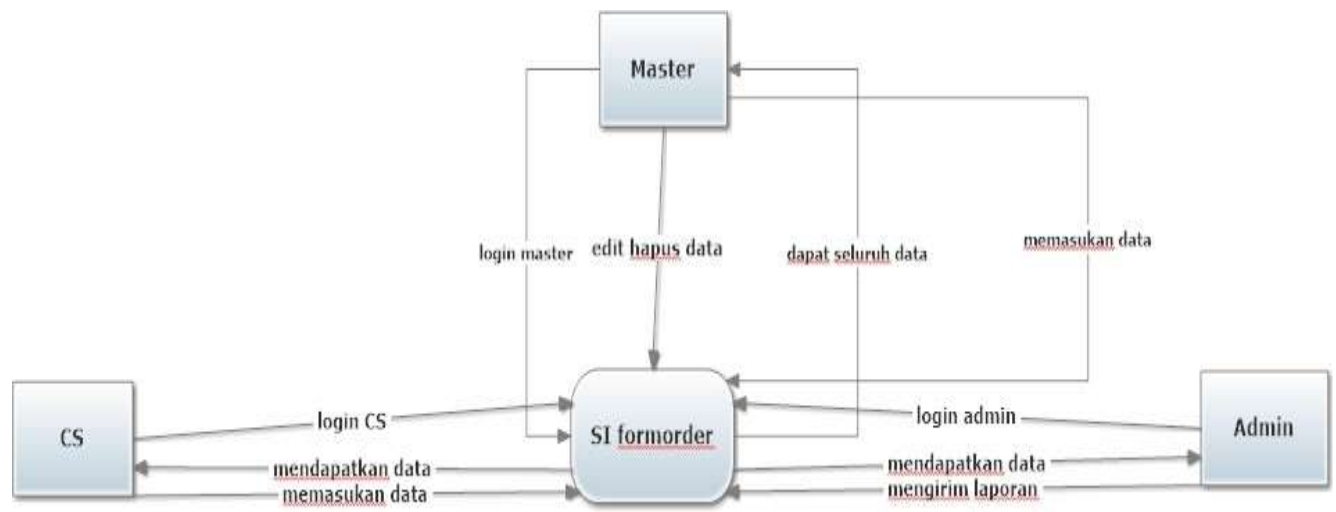

Gambar 1 Diagram Konteks Sistem Informasi Formorder

Dapat dilihat pada diagram konteks tersebut terdapat tiga entitas yaitu CS, Master, dan Admin. Masingmasing entitas memiliki alur masuk dan keluar dari dan ke dalam Sistem Informasi Form Order. Entitas CS diharuskan untuk login ke dalam sistem agar bisa memasukkan data dan mendapatkan data dari dalam sistem. Kemudian entitas Admin pun harus melakukan proses login ke dalam sistem agar dapat mengirim laporan dan mendapatkan data. Sedangkan entitas Master juga sama harus melakukan prosedur login agar dapat mengelola data yang ada di dalam sistem ini.

\section{Entity Relationship Diagram}

Entity Relationship Diagram adalah sebuah diagram alir yang mengilustrasikan bagaimana sebuah entitas seperti orang, obyek atau sebuah konsep dapat terhubung satu sama lain di dalam sebuah sistem. 
Diagram ini sering digunakan untuk menggambarkan relasi dari tabel dalam sebuah basis data sistem informasi, pendidikan maupun penelitian [6].

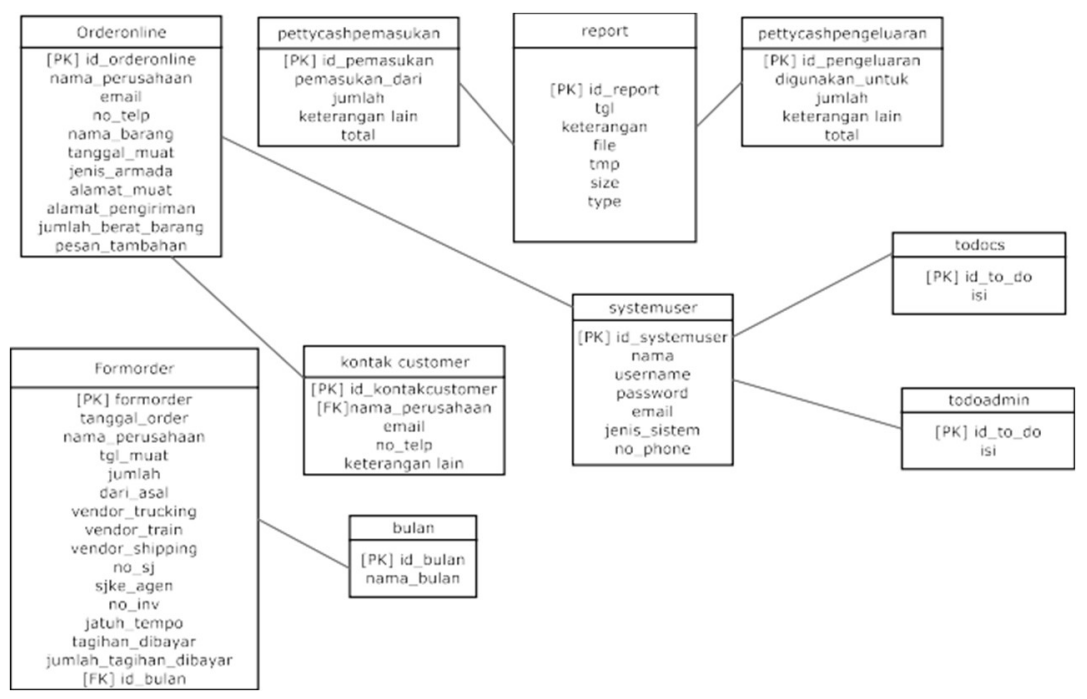

\section{Gambar 2 Entity Relationship Diagram}

Seperti pada gambar, tabel-tabel yang terdapat dalam basis data sistem ini adalah, tabel orderonline, pettycashpemasukan, report, pettycashpengeluaran, formorder, kontak customer, bulan, systemuser, todocs, dan todoadmin di mana masing-masing memiliki atribut dan juga Primary Key (PK) dan Foreign Key (FK).

\section{Kamus Data}

1. Kamus Data Tabel Form Order

Tabel 1 Tabel form Order

\begin{tabular}{|l|c|c|c|}
\hline Nama Field & Tipe Data & Value & Key \\
\hline id_formorder & Integer & 11 & PK \\
\hline Bulan_id & varchar & 255 & \\
\hline tanggal_order & varchar & 255 & \\
\hline Nama_perusahaan & varchar & 255 & \\
\hline jumlah & varchar & 255 & \\
\hline Dari_asal & varchar & 255 & \\
\hline Vendor_trucking & varchar & 255 & \\
\hline Vendor_train & varchar & 255 & \\
\hline Vendor_shipping & varchar & 255 & \\
\hline No_sj & varchar & 255 & \\
\hline No_invoice & varchar & 255 & \\
\hline Jatuh tempo & Varchar & 255 & \\
\hline Tagihan dibayar & Varchar & 255 & \\
\hline $\begin{array}{l}\text { Jumlah tagihan } \\
\text { dibayar }\end{array}$ & varchar & 255 & \\
\hline
\end{tabular}


2. Kamus Data Tabel Pettycash pemasukan

Tabel 2 Tabel pettycash permasukan

\begin{tabular}{|l|l|l|l|}
\hline Nama Field & Tipe Data & Value & Key \\
\hline id_pemasukan & integer & 11 & PK \\
\hline Pemasukan_dari & varchar & 255 & \\
\hline jumlah & varchar & 255 & \\
\hline Keterangan_lain & varchar & 255 & \\
\hline total & varchar & 255 & \\
\hline
\end{tabular}

3. Kamus Data Tabel pettycash pengeluaran

Tabel 3 Tabel pengeluaran

\begin{tabular}{|c|c|c|c|}
\hline Nama Field & Tipe Data & Value & Key \\
\hline id_pengeluaran & integer & 11 & PK \\
\hline digunakan & varchar & 255 & \\
\hline jumlah & varchar & 255 & \\
\hline Keterangan_lain & varchar & 255 & \\
\hline
\end{tabular}

4. Kamus Data Tabel Bulan

Tabel 4 Tabel bulan

\begin{tabular}{|c|r|c|r|}
\hline Nama Field & Tipe Data & Value & Key \\
\hline id_bulan & integer & 11 & PK \\
\hline nama_bulan & varchar & 255 & \\
\hline
\end{tabular}

5. Kamus Data Tabel contactcustomer

Tabel 5 Tabel contactcusomer

\begin{tabular}{|l|l|l|l|}
\hline \multicolumn{1}{|c|}{ Nama Field } & Tipe Data & Value & Key \\
\hline Id_contactcustomer & integer & 11 & PK \\
\hline Nama perusahaan & varchar & 255 & FK \\
\hline email & varchar & 255 & \\
\hline No_telp & Varchar & 255 & \\
\hline Keterangan_lain & Varchar & 255 & \\
\hline
\end{tabular}

6. Kamus Data Tabel orderonline

Tabel 6 Tabel orderonline

\begin{tabular}{|c|c|c|c|}
\hline Nama Field & Tipe Data & Value & Key \\
\hline Id_orderonline & integer & 11 & PK \\
\hline Nama_perusahaan & varchar & 255 & \\
\hline email & varchar & 255 & \\
\hline No_telp & varchar & 255 & \\
\hline Nama_barang & varchar & 255 & \\
\hline Tanggal_muat & varchar & 255 & \\
\hline Jenis_armada & Varchar & 255 & \\
\hline Alamat_muat & Varchar & 255 & \\
\hline Alamat_pengiriman & varchar & 255 & \\
\hline
\end{tabular}




\begin{tabular}{|c|l|l|l|}
\hline Jumlah_berat_barang & varchar & 255 & \\
\hline Pesan_tambahan & varchar & 255 & \\
\hline
\end{tabular}

7. Kamus Data Tabel report

Tabel 7 Tabel report

\begin{tabular}{|c|c|c|c|}
\hline Nama Field & Tipe Data & Value & Key \\
\hline Id_report & integer & 11 & PK \\
\hline tgl & date & 255 & \\
\hline keterangan & varchar & 255 & \\
\hline file & varchar & 255 & \\
\hline tmp & varchar & 255 & \\
\hline size & varchar & 255 & \\
\hline type & varchat & 255 & \\
\hline
\end{tabular}

8. Kamus Data Tabel systemuser

Tabel 8 Tabel systemuser

\begin{tabular}{|c|c|c|c|}
\hline Nama Field & Tipe Data & Value & Key \\
\hline Id_systemuser & integer & 11 & PK \\
\hline nama & date & 255 & \\
\hline username & varchar & 255 & \\
\hline email & varchar & 255 & \\
\hline Jenis_sistem & enum & & \\
\hline phone & varchar & 255 & \\
\hline \multicolumn{4}{|l}{}
\end{tabular}

9. Kamus Data Tabel todo admin

Tabel 9 Tabel todo admin

\begin{tabular}{|c|c|c|c|}
\hline Nama Field & Tipe Data & Value & Key \\
\hline Id_todoadmin & integer & 11 & PK \\
\hline todoadmin & varchar & 255 & \\
\hline
\end{tabular}

10. Kamus Data Tabel todo CS

Tabel 10 Tabel todocs

\begin{tabular}{|c|c|c|c|}
\hline Nama Field & Tipe Data & Value & Key \\
\hline Id_todocs & integer & 11 & PK \\
\hline todocs & varchar & 255 & \\
\hline
\end{tabular}

\section{Perancangan Antar Muka}

Perancangan antar muka berfokus dalam mengantisipasi apa yang sekiranya pengguna akan lakukan dan memastikan bahwa tampilan memiliki elemen yang mudah untuk dipahami dan diakses dalam memfasilitasi kebutuhan pengguna. Perancangan antar muka memiliki konsep rancangan yang interaktif, rancangan berbasis visual dan arsitektur informasi [7].

Pada bagian ini akan dijelaskan hasil perancangan sistem informasi pencatatan form order berbasis web pada PT. United Trans Perkasa. 


\section{Tampilan Antar Muka Login}

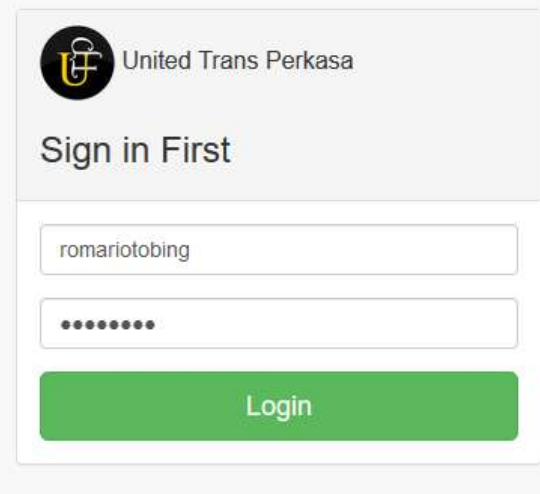

Gambar 3 Halaman Login

Gambar 3 adalah tampilan halaman antar muka untuk proses login. User/admin diwajibkan untuk login ke dalam sistem apabila ingin mengakses data yang terdapat di dalam sistem.

\section{Tampilan Antar Muka Home Master}

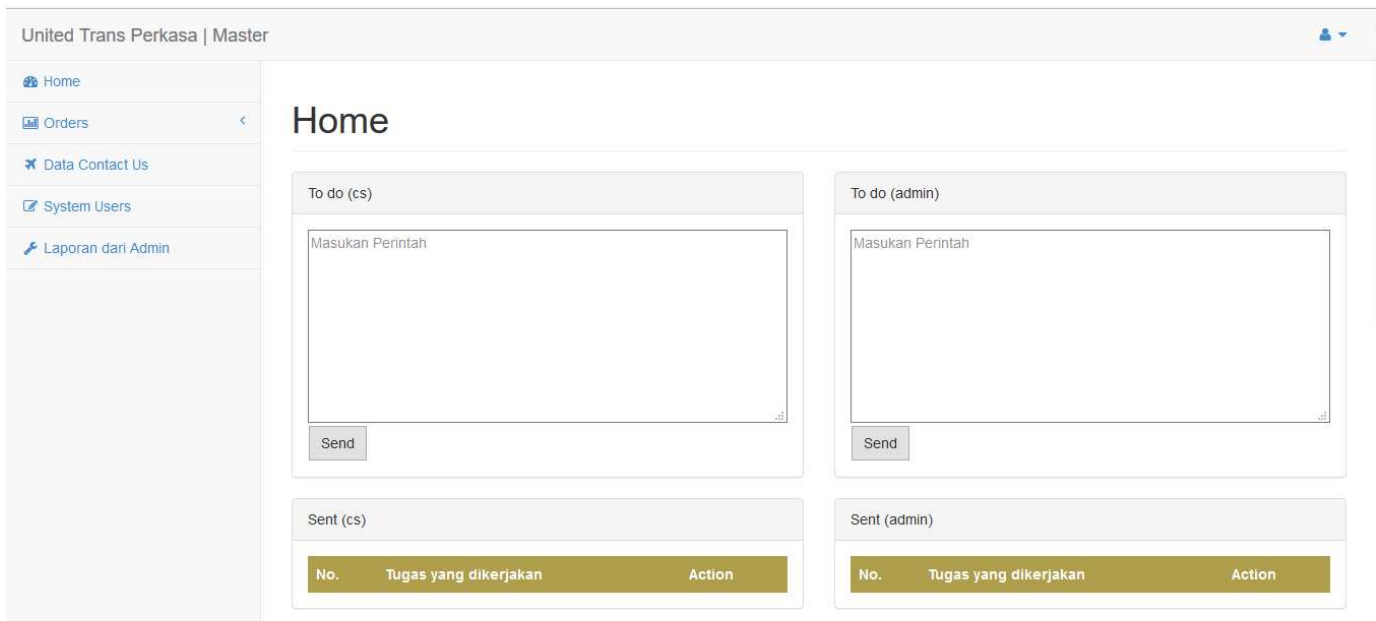

Gambar 4 Halaman Home Master

Gambar 4 menunjukkan tampilan halaman utama ketika user/admin sudah melakukan login ke dalam sistem. User/admin dapat memilih menu yang terdapat di sebelah kiri layar dan juga melihat tugas yang sedang dikerjakan oleh cs ataupun admin.

\section{Tampilan Antar Muka Data Order}

Gambar 5 menunjukkan tampilan antar muka untuk data order dari perusahaan yang ingin menggunakan jasa pengiriman barang dari PT. United Trans Perkasa ini. Dapat dilihat juga status pemesanan/order beserta dengan proses dan pembayarannya. 


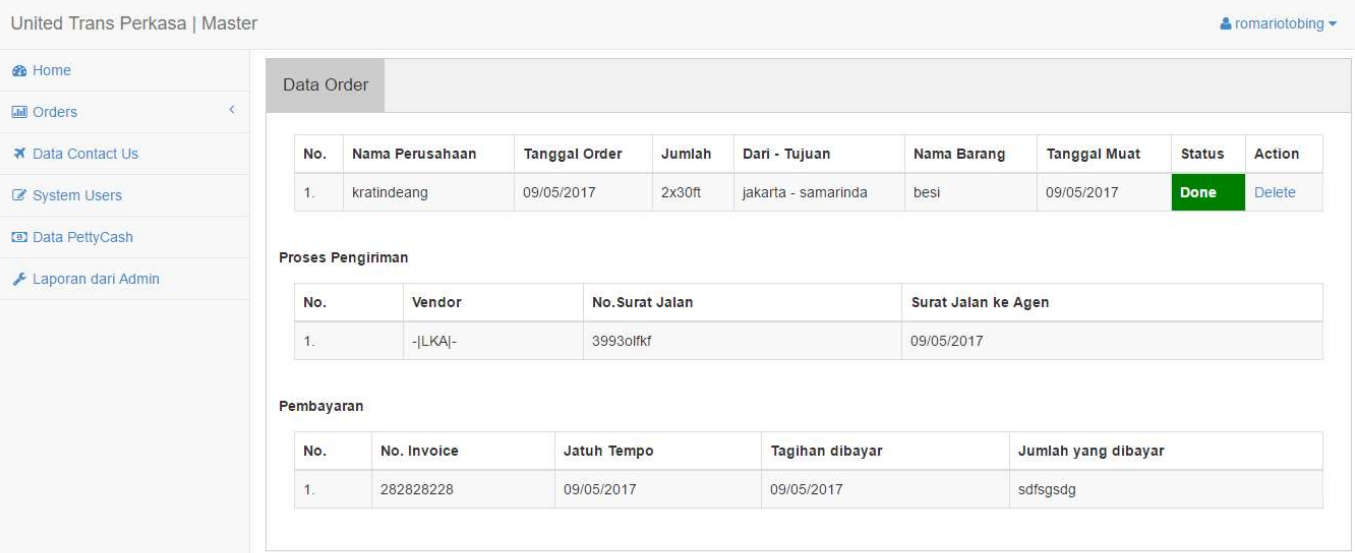

Gambar 5 Halaman data order

\section{Tampilan Antar Muka Report}

\begin{tabular}{|c|c|c|c|c|c|}
\hline \multicolumn{6}{|l|}{ United Trans Perkasa | Master } \\
\hline Home & Report & & & & \\
\hline 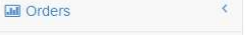 & No. & Tanggal & Keterangan & File & Action \\
\hline * Data Contact Us & 1 & $2017-04-23$ & tessssss & Struktur_Data_Array (1).docx & Delete \\
\hline (8) System Users & & & & & \\
\hline
\end{tabular}

Gambar 6 Halaman Report

Pada gambar 6 ini ditunjukkan tampilan antar muka untuk halaman report atau laporan. Di sini terlihat berkas yang telah dilaporkan beserta dengan tanggal laporan dan keterangannya.

\section{Tampilan Antar Muka Form Order}

Pada halaman halaman ini (Gambar 7) CS akan mengisi semua data order. CS dapat memasukan data satu per satu ke dalam form yang sudah disediakan. Jika sudah selesai meng input maka CS akan menekan tombol simpan dan sistem akan mengirim pengguna sistem sesuai dengan bulan di mana pengguna memasukan data tersebut. Jika pengguna ingin mengulang mengisi data, dapat dengan menekan tombol reset disebelah tombil simpan. Lalu ada link untuk melihat data order. Dengan mengklik link tersebut maka pengguna sistem akan diminta untuk memilih bulan dan akan masuk ke bulan yang dipilih. 


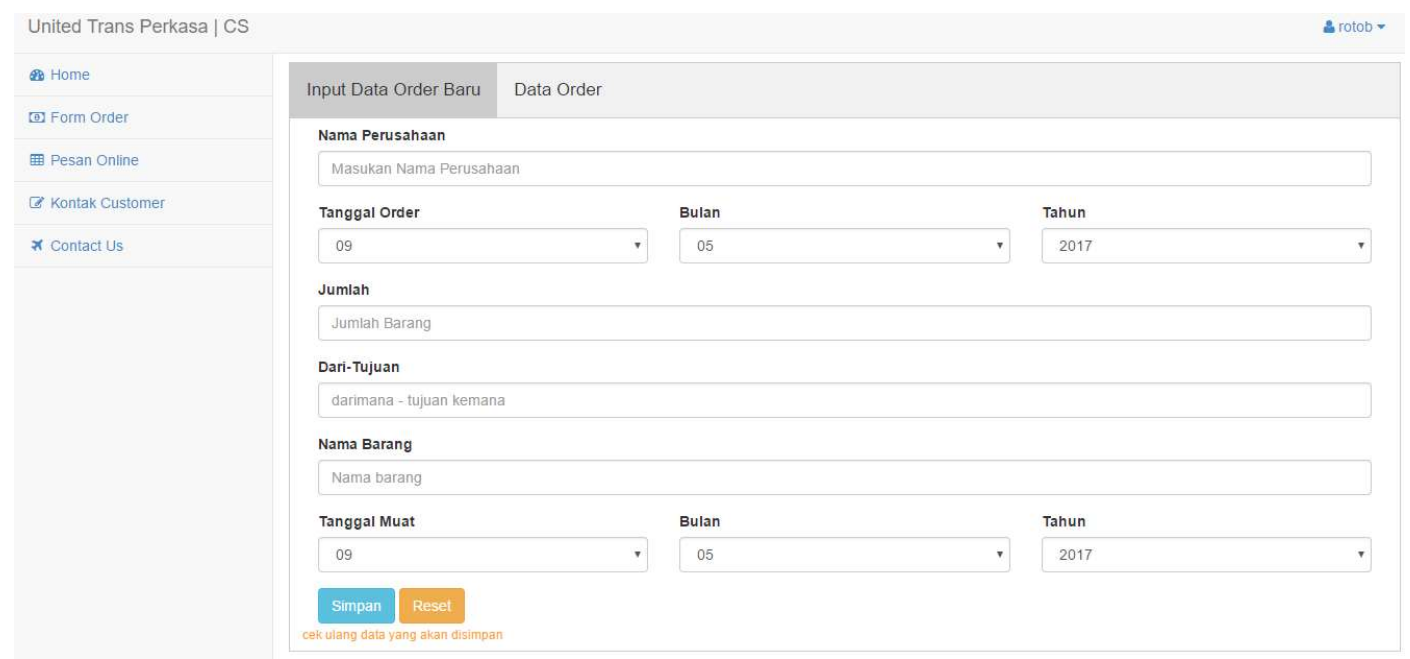

Gambar 7 Halaman Form order

\section{Tampilan Antar Muka Pettycash}

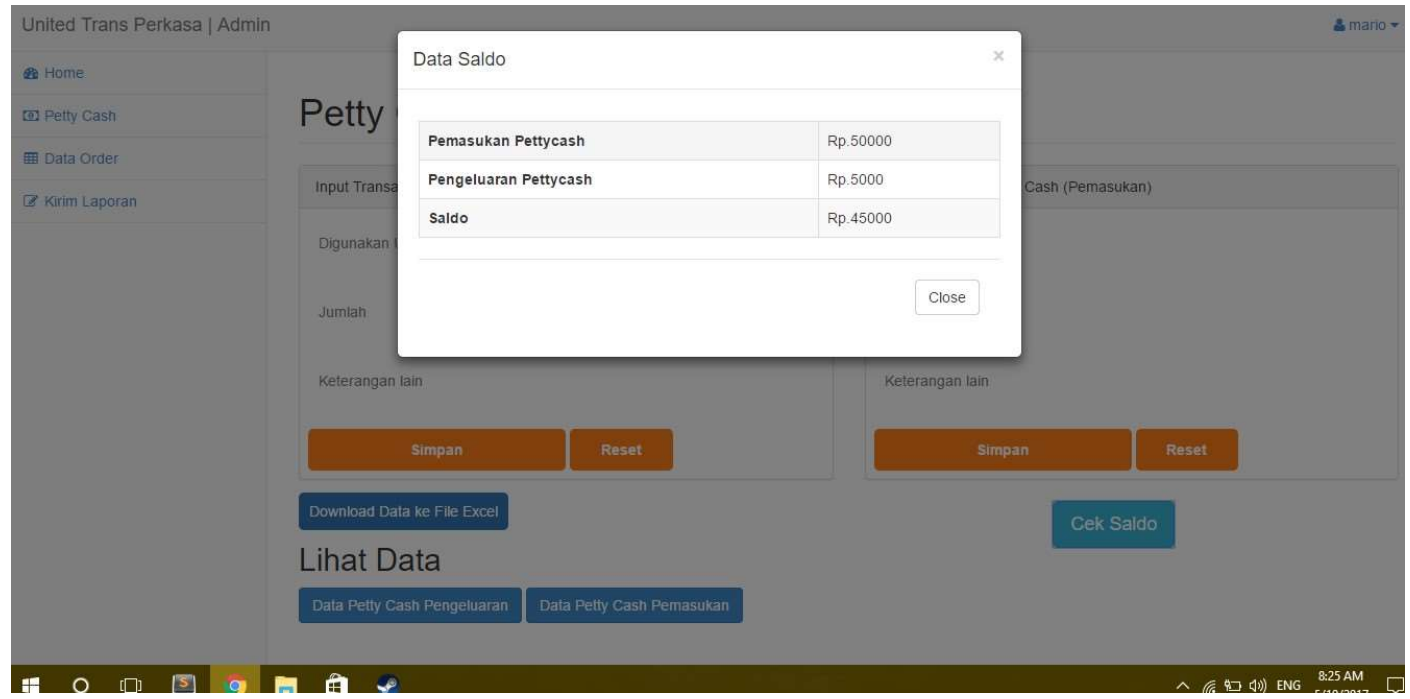

Gambar 8 Halaman Pettycash

Pettycash adalah kas kecil di sebuah perusahaan, dan data pettycash akan diatur dan dilaporkan oleh admin. Jadi di halaman ini admin dapat memasukan data pettycash dan dapat dengan mudah mendapatkan data pengeluaran dan pemasukannya. Data pengeluaran atau pemasukan pettycash ini dapat dilihat dengan menekan tombol yang ada di bawah form pengisian. Jika tombol di klik maka data akan terlihat ke bawah. Admin juga dapat melakukan perubahan bahkan menghapus data pettycash dengan mengklik kedua tombol tersebut masing-masing. Untuk melihat saldo pettycash, admin dapat mengklik tombol cek saldo yang ada di kanan bawah halaman dan akan terlihat data saldo. 


\section{Kesimpulan}

Kesimpulan dari penelitian ini adalah:

1. Sistem informasi pencatatan form order pada PT. United Trans Perkasa adalah sistem yang dibuat untuk mempermudah pekerjaan dan juga meningkatkan pelayanan dalam melayani para customer.

2. Sistem informasi pencatatan form order pada PT. United Trans Perkasa dapat menyajikan data yang penting dalam perusahaan secara terkomputerisasi dan juga berbasis online, sehingga data tersebut bisa diakses oleh pekerja kantor di mana dan kapan saja.

3. Sistem informasi pencatatan form order pada PT. United Trans Perkasa juga dapat memudahkan pihak perusahaan dalam mengecek customer yang ingin menggunakan jasa pihak perusahaan, karena sistem ini terhubung dengan website perusahaan.

Adapun saran yang dapat diberikan untuk penelitian selanjutnya adalah:

1. Sistem ini dapat ditambah fiturnya seperti fitur chat antara masing-masing sistem seperti global chat untuk pihak master, admin, dan CS.

2. Sistem informasi ini dapat dikembangkan lagi dengan dibuatnya fungsi pengerjaan tahap per tahap agar dapat mempermudah bagian manajemen dalam mengontrol pekerjaan dalam kantor.

3. Dapat ditambahkan halaman keuangan agar pihak perusahaan khususnya bidang keuangan dapat lebih mudah mengontrol data dan juga laporan keuangan perusahaan.

\section{Referensi}

[1] Hutahaean, J. "Konsep Sistem Informasi." Yogyakarta. Deepublish. 2014.

[2] Sibero, A. F. K. "Kitab Suci Web Programming." Jakarta. Mediakom. 2012.

[3] Connolly, T and Begg, C. "Database Systems A Practical Approach to Design, Implementation, and Management Fifth Edition." United Kingdom. Pearson Education. 2010.

[4] A.S Rosa dan Salahuddin M. "Modul Pembelajaran Rekayasa Perangkat Lunak (Terstruktur dan Berorientasi Objek)." Bandung. Modula. 2011.

[5] https://www.cs.uct.ac.za/mit_notes/software/htmls/ch06s06.html

[6] https://www.lucidchart.com/pages/er-diagrams

[7] https://www.usability.gov/what-and-why/ user-interface-design.html 